\title{
A INTERIORIZAÇÃODA EAD NAS INSTITUIÇÕES PÚBLICAS DE EDUCAÇÃO \\ NO ESTADO DE MATO GROSSO DO SUL: AVANÇOS E PERSPECTIVAS
}

\author{
INTERIORIZATION DISTANCE LEARNING IN PUBLIC INSTITUTIONS OF \\ EDUCATION IN THE STATE OF MATO GROSSO DO SUL: ADVANCES AND \\ PERSPECTIVES
}

Resumo: O objetivo deste trabalho é analisar o processo de interiorização ${ }^{1}$ da educação à distância nas instituições públicas encontradas no estado de Mato Grosso do Sul, seja nas etapas da educação básica ou superior, seja na modalidade profissional. Os procedimentos metodológicos utilizados são: a pesquisa bibliográfica; pesquisa documental e análise qualiquantitativa. A interiorização da educação à distância no setor público de ensino vem reforçando a necessidade do processo de institucionalização dessa modalidade, pois os polos na qual atuam as instituições públicas são em municípios do interior do estado mas instituições vem sofrendo cortes de verbas para sua manutenção.

Palavras-chave: Educação à distância. Interiorização da EaD. Instituições públicas. Institucionalização.

Abstract: The objective of this paper is to analyze the process of internalization of distance education in public institutions found in the state of Mato Grosso do Sul, either in the stages of basic or higher education, or in the professional mode. The methodological procedures used are: bibliographic research; documentary research and qualiquantitative analysis. The internalization of distance education in the public education sector has reinforced the need for the institutionalization process of this modality, since the poles in which the public institutions operate are in municipalities in the interior of the state but the institutions have been suffering funding cuts for their maintenance.

Keywords: Distance Education. Internalization of distance education. Public institutions. Institutionalization.

\section{Introdução}

\footnotetext{
${ }^{1}$ Ato de levar algo que existe nos grandes centros ou na capital para municípios menores do interior do estado. No caso deste trabalho, seria a expansão de cursos na modalidade à distância que estariam sendo implantados em municípios do interior do estado.
} 


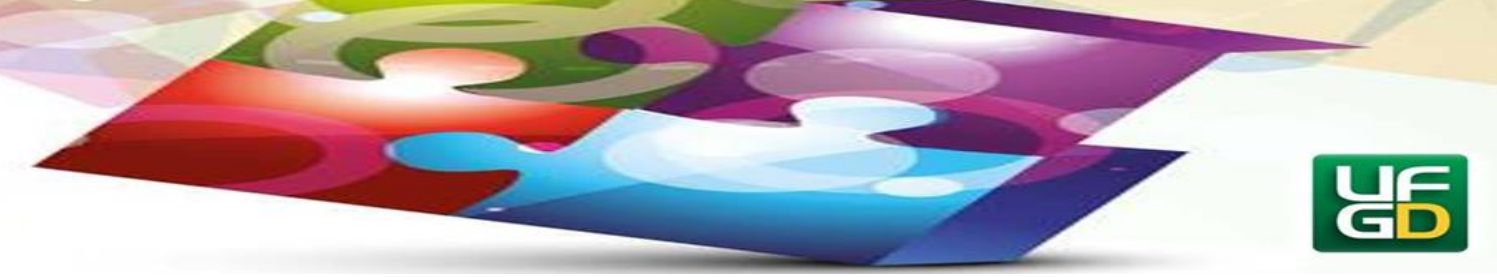

A educação é um processo histórico e transitório que sofre alterações de acordo com o contexto socioeconômico desde o local ao global, sendo muitas vezes, necessário se adequar as necessidades dos seus alunos e do processo de ensino-aprendizagem. É fundamental o acompanhamento dessa evolução pelos professores, uma vez que tais transformações geram consequências sociais, econômicas, políticas e tecnológicas. Daí surge a educação à distância.

De acordo com Amorim (2008), o início da Educação à Distância (EaD) no mundo se deu na Suécia no ano de 1833 com o primeiro curso de contabilidade realizado via correspondência. Em consonância com Alves (2011), houve várias experiências feitas pela Europa e Estados Unidos envolvendo essa modalidade de ensino, e foi a partir do século XIX que ela passou a ser oferecida e trabalhada institucionalmente para o restante do globo.

Com isso, a sociedade atual vem se transformando na atualidade e a educação precisa acompanhar tais mudanças. O capitalismo desenvolveu cada vez mais os meios tecnológicos ou o meio técnico-científico-informacional ${ }^{2}$.

$\mathrm{Na}$ educação, esses processos geraram impactos nas práticas pedagógicas, desde a educação infantil ao ensino superior. Dessa forma, coube aos espaços de ensino e formação (escolas, creches, universidades, institutos, etc.), promover uma educação de qualidade e formar pessoas críticas, além de facilitar o acesso aos meios tecnológicos disponíveis, principalmente, ao computador e à internet.

Nesse contexto, no Brasil, surge a Educação a Distância como uma modalidade de educação que possibilita distintas formas de aprendizagem, por meio de diferentes formas de ver o mundo, de ensinar e aprender e utilizando técnicas que, até a pouco eram deixadas de lado e/ou nem sequer existiam, como vídeos, links, webconferências, chats online, plataformas de ensino, aplicativos de celulares, entre outros.

\footnotetext{
${ }^{2}$ De acordo com Milton Santos (1996), o meio técnico-científico- informacional corresponde a evolução das transformações do espaço geográfico, ou seja, transformações do meio natural, meio técnico, meio científico e meio informacional. Representa assim, o estágio atual do desenvolvimento do sistema capitalista e suas transformações no espaço geográfico. Dessa forma, houve a junção entre a ciência e a técnica, orientadas pelo capital, utilizando-se dos avanços tecnológicos para expandir o processo de globalização que pode ser perversa.
} 


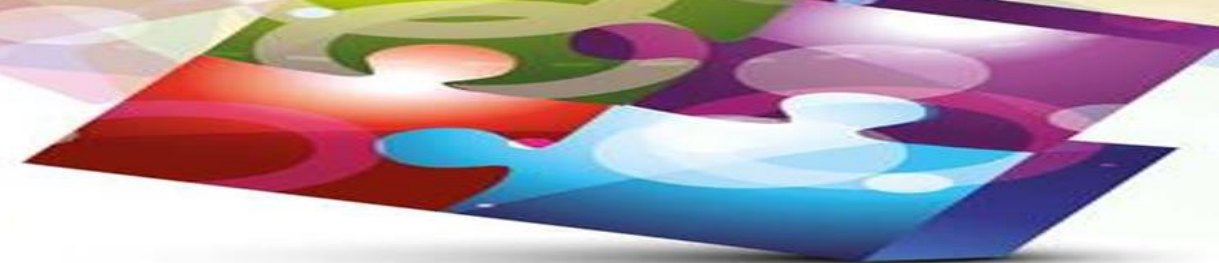

Essa conjuntura trouxe aspectos positivos ao contexto educacional, principalmente no processo de democratização do acesso ao ensino em locais distantes dos grandes centros urbanos.

Assim, nosso objetivo neste trabalho é analisar a interiorização dos cursos de nível superior no estado do Mato Grosso do Sul nas instituições públicas de ensino, seja no âmbito estadual ou federal. Além disso, fazer uma breve discussão sobre os avanços e perspectivas dessa interiorização.

As metodologias utilizadas para a discussão deste trabalho foram: a pesquisa bibliográfica sobre a educação a distância no Brasil e os avanços que ela vem sofrendo; pesquisa documental em sites, leis e normas que direcionam seus esforços para essa discussão; e análise qualiquantitativa sobre as informações obtidas.

A educação à distância tem provocado várias discussões no âmbito acadêmico, o que demonstra o interesse pelo tema. Dessa forma, convém destacar o processo de evolução pela qual essa modalidade de educação passou, uma vez que, inúmeros cursos foram criados e difundidos Brasil afora. Assim, destacamos o processo de construção e reafirmação dessa modalidade apresentando seu processo histórico e sua normatização.

\section{A evolução da educação a distância no Brasil}

O primeiro experimento de EAD no Brasil aconteceu em 1923 pelas ondas do rádio da Fundação da Rádio Sociedade do Rio de Janeiro. Em 1939, criou-se o Instituto Rádio Monitor que pensava em utilizar as ondas dos rádio para o ensino. Daí em diante, foram surgindo vários projetos de Educação a Distância, quase sempre sob a tutela estatal (1956 - Movimento de Educação de Base e 1970 - Projeto Minerva) (KENSKI, 2010).

Já em 1996 a LDB (Lei de Diretrizes e Bases da Educação Nacional) passa a regulamentar a $\mathrm{EaD}$ em seu artigo 80 , com o seguinte texto:

Art. 80 - O Poder Público incentivará o desenvolvimento e a veiculação de programas de ensino a distância, em todos os níveis e modalidades de ensino, e da educação continuada.

$\S 11^{\circ}$ A educação a distância, organizada com abertura e regime especiais, será oferecida por instituições especificamente credenciadas pela União.

$\S 2 .^{\circ}$ A União regulamentará os requisitos para a realização de exames e registro de diploma relativos a cursos de educação a distância. 


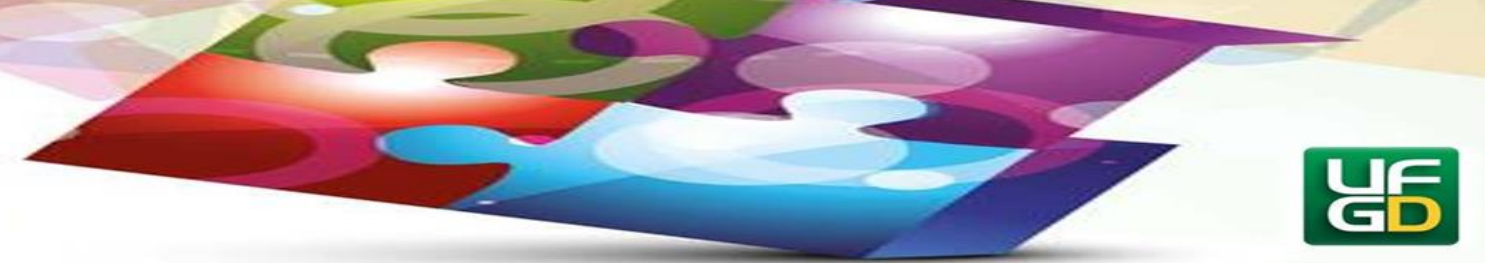

§ 3..$^{\circ}$ As normas para produção, controle e avaliação de programas de educação a distância e a autorização para sua implementação, caberão aos respectivos sistemas de ensino podendo haver cooperação e integração entre os diferentes sistemas.

$\S 4 .^{\circ}$ A educação a distância gozará de tratamento diferenciado, que incluirá: I - custos de transmissão reduzidos em canais comerciais de radiodifusão sonora e de sons e imagens;

II - concessão de canais com finalidades exclusivamente educativas; III reserva de tempo mínimo, sem ônus para o Poder Público, pelos concessionários de canais comerciais.

Esse foi um dos marcos para alavancar o processo de Educação à Distância no Brasil, levando em consideração o tamanho do território nacional e que muitos cursos estavam centralizados nos grandes centros urbanos, ou seja, houve um processo de alargamento dos cursos a distância Brasil afora. Outro marco importante foi por meio da efetiva utilização dos meios tecnológicos de informação e comunicação (TICs).

Com as TICs não há a necessidade dos professores e alunos estarem no mesmo espaço físico e todos ao mesmo tempo e a Educação à Distância veio sanar um dos principais problemas num país de tamanho continental como o Brasil (a distância física). Assim os cursos superiores, principalmente, espalharam por institutos, faculdades e universidades públicas e privadas.

No setor público, a difusão dos cursos se deu após a criação da Universidade Aberta do Brasil (UAB) em 2005, que tinha como objetivo expandir a oferta de cursos de educação superior em instituições públicas no interior do Brasil, principalmente nos lugares mais distantes dos grandes centros.

Dessa forma a UAB passou a oferecer cursos técnicos, profissionalizantes, de aperfeiçoamento, de graduação, pós-graduação, entre outros. Tais cursos sucederam de uma forma de ensino-aprendizagem mediada por tecnologias permitindo que o professor e o estudante estejam em ambientes físicos e espaços temporais distintos. Assim o estudante passa a organizar seus horários de estudo de acordo com sua rotina diária de atividades como trabalho, lazer, afazeres domésticos, etc. Além disso, pode acessar a plataforma de estudos em qualquer lugar com seu computador portátil, tablet, celular, entre outros. 


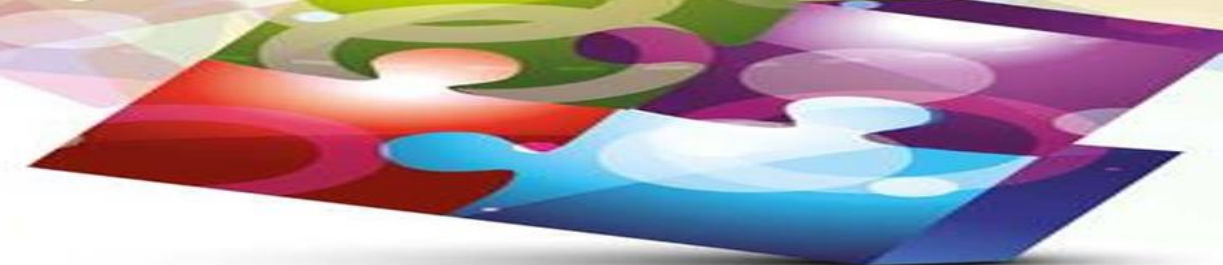

Essa nova forma de ensino-aprendizagem demonstra a autonomia dos alunos e dos professores numa comunicação que pode ser síncrona ${ }^{3}$ e/ou assíncrona ${ }^{4}$. Por sua vez, os alunos podem definir o melhor local e horário para estudar, conforme seu ritmo de aprendizado, utilizando materiais didáticos que facilitam a mediação dos conhecimentos, promovendo a autoaprendizagem.

De acordo com o Decreto n 5.622 de 2005, no Art. $1^{\circ}$, este caracteriza a Educação à Distância como sendo uma modalidade educacional em que a mediação didático-pedagógica nos processos de ensino e aprendizagem ocorrem com o uso de meios e tecnologias de comunicação e informação, além de alunos e professores desenvolvendo atividades educativas em lugares ou tempos distintos e distantes.

Ainda de acordo com o decreto existem alguns momentos que são presenciais obrigatórios como avaliações presenciais das disciplinas, estágios obrigatórios, defesa de trabalhos de conclusão de curso e atividades de laboratórios de ensino. No entanto, parte desse decreto foi alterado pelo Decreto $n^{\circ} 9.057$ de 25 de maio de 2017 que desobriga os cursos a distância a realizar encontros presenciais, apenas em cursos que tiverem especificado essa questão em seu Projeto Pedagógico do Curso.

A legislação vigente considera a educação à distância como uma modalidade de ensino que se utiliza de meios tecnológicos para estabelecer uma interação entre professor-aluno e/ou aluno-aluno visando uma aprendizagem de forma colaborativa e conjunta.

No entanto, essa comunicação e aprendizagem não são tão significativas quando partimos para a análise da realidade dos municípios brasileiros, pois enquanto existem municípios que tem internet com tecnologia e velocidade $5 \mathrm{G}$, outros tem internet $2 \mathrm{G}$ intermitente, como é o caso de alguns municípios sul-mato-grossense.

De acordo com Preti (2000), a maior parte dos alunos dos cursos oferecidos via Educação a Distância demonstram características peculiares, como por exemplo: são adultos

\footnotetext{
${ }^{3}$ Como forma síncrona (quando alunos e professores estão conectados ao mesmo tempo), podemos destacar a webconferência, as aulas ao vivo, grupos de chats ao vivo, reuniões por telefone, etc.

${ }^{4}$ Como forma assíncrona (quando alunos e professores não estão conectados ao mesmo tempo), visualizamos várias formas como grupos em aplicativos de conversas, vídeos gravados, filmes, anúncios, imagens, links, fóruns, entre outros.
} 


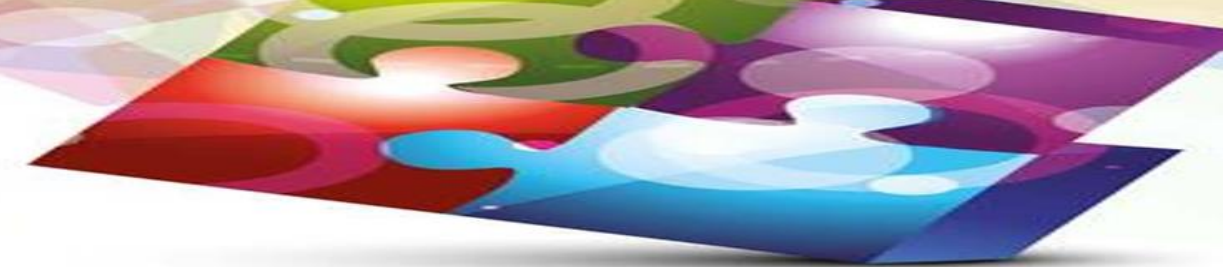

que já atuam no mercado de trabalho e não residem em locais próximos das instituições de ensino, além de terem pouco tempo para estudar no ensino regular presencial, necessitando de um ensino mais flexível e que se encaixe em suas necessidades.

As instituições (escolas, faculdades, universidades, institutos, etc.) que passam a utilizar a Educação a Distância em seu processo de ensino e aprendizagem conseguem romper com as barreiras temporais e geográficas como é o caso das instituições públicas analisadas no estado do Mato Grosso do Sul.

\section{A interiorização da educação a distância nas instituições públicas do Mato Grosso do Sul}

As alterações sofridas na economia mundial atinge a todos no que diz respeito ao mercado de trabalho, o que requer transformações nos sistemas educacionais para além das formas tradicionais de ensino-aprendizagem, uma vez que o mercado de trabalho está cada vez mais exigente quanto aos sujeitos que adentram-no, ou seja, exige-se pessoas com competências múltiplas que tenham capacidade de aprender e de adaptar-se a situações diversas.

Assim, o processo de interiorização da Educação à Distância nas instituições públicas do estado do Mato Grosso do Sul vem acompanhando a expansão do ensino superior nas universidades e institutos federais, além da criação, ampliação e financiamento da Universidade Aberta do Brasil (UAB). A expansão da educação a distância está amparado por diversas leis e decretos (Quadro 1) dos quais se destacam:

\section{Quadro 1 - Normatização da EaD no Brasil}

\begin{tabular}{|c|c|}
\hline Lei/Decreto & Regulamentação \\
\hline $\begin{array}{l}\text { Lei no } 9.394 \\
1996\end{array}$ & $\begin{array}{l}\text { Artigo } 80 \text { que estabelece que o Poder Público incentivará o desenvolvimento } \\
\text { e a veiculação de programas de ensino a distância, em todos os níveis e } \\
\text { modalidades de ensino, e de educação continuada. }\end{array}$ \\
\hline $\begin{array}{l}\text { Decreto } n^{\circ} 2.494 \\
1998\end{array}$ & Este Decreto regulamenta o Artigo 80 da LDB (Lei no 9.394/96). \\
\hline $\begin{array}{l}\text { Decreto } n^{\circ} 2561 \\
1998\end{array}$ & $\begin{array}{l}\text { Altera o Artigo } 11 \text { do Decreto } \mathrm{n}^{\circ} 2.494 / 98 \text {, incluindo o credenciamento de } \\
\text { instituições de educação profissional de nível tecnológico e Artigo } 12 \text { onde } \\
\text { amplia a oferta de cursos da EaD para a educação profissional. }\end{array}$ \\
\hline
\end{tabular}




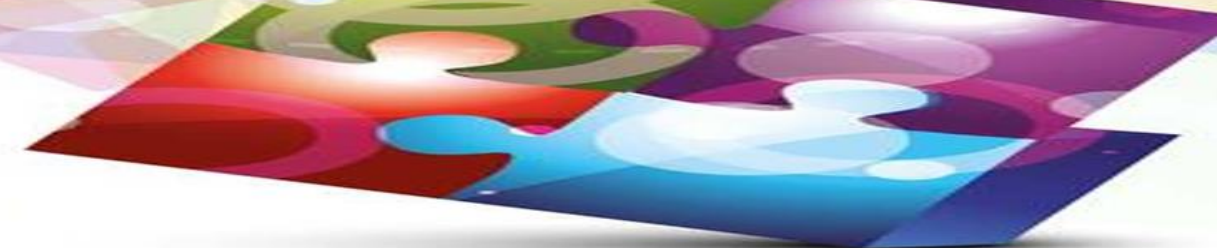

\begin{tabular}{|c|c|}
\hline $\begin{array}{l}\text { Portaria } \\
\text { Ministerial } \\
4.361 \\
2004\end{array}$ & $\begin{array}{l}\text { Trata dos processos de credenciamento e recredenciamento de instituições } \\
\text { de educação superior (IES), credenciamento para oferta de cursos de pós- } \\
\text { graduação lato sensu, credenciamento e recredenciamento de instituições de } \\
\text { educação superior para oferta de cursos superiores a distância }\end{array}$ \\
\hline $\begin{array}{l}\text { Decreto } n^{\circ} 5.622 \\
2005\end{array}$ & Regulamenta o Artigo 80 da Lei nº 9.394/96. \\
\hline $\begin{array}{l}\text { Decreto } n^{\circ} 5.800 \\
2006\end{array}$ & Institui o Sistema Universidade Aberta do Brasil (UAB) \\
\hline $\begin{array}{l}\text { Portaria } \\
\text { Normativa } n^{\circ} 2 \\
2007\end{array}$ & $\begin{array}{l}\text { Dispõe sobre os procedimentos de regulação e avaliação da educação superior na } \\
\text { modalidade a distância. }\end{array}$ \\
\hline $\begin{array}{l}\text { Portaria } \\
\text { Normativa } n^{\circ} 40 \\
2010\end{array}$ & $\begin{array}{l}\text { Institui o e-MEC, sistema eletrônico de fluxo de trabalho e gerenciamento de } \\
\text { informações relativas aos processos de regulação, avaliação e supervisão da } \\
\text { educação superior, o Cadastro e-MEC, Basis e o ENADE. }\end{array}$ \\
\hline $\begin{array}{l}\text { Decreto } n^{\circ} 9.057 \\
2017\end{array}$ & $\begin{array}{l}\text { Regulamenta o art. } 80 \text { da Lei no } 9.394 \text {, de } 20 \text { de dezembro de 1996, que estabelece } \\
\text { as diretrizes e bases da educação nacional. }\end{array}$ \\
\hline $\begin{array}{l}\text { Portaria } \\
\text { Normativa } \mathrm{n}^{\mathrm{o}} 11 \\
2017\end{array}$ & $\begin{array}{l}\text { Estabelece normas para o credenciamento de instituições e a oferta de cursos } \\
\text { superiores a distância, em conformidade com o Decreto } n^{\circ} 9.057 \text {, de } 25 \text { de maio de } \\
2017\end{array}$ \\
\hline $\begin{array}{l}\text { Portaria } \\
\text { Normativa } n^{\circ} 22 \\
2017\end{array}$ & $\begin{array}{l}\text { Dispõe sobre os procedimentos de supervisão e monitoramento de instituições de } \\
\text { educação superior e de cursos superiores de graduação e de pós-graduação lato } \\
\text { sensu, nas modalidades presencial e a distância. }\end{array}$ \\
\hline $\begin{array}{l}\text { Portaria } \\
\text { Normativa } n^{\circ} 23 \\
2017\end{array}$ & $\begin{array}{l}\text { Dispõe sobre os fluxos dos processos de credenciamento e recredenciamento de } \\
\text { instituições de educação superior e de autorização, reconhecimento e renovação de } \\
\text { reconhecimento de cursos superiores, bem como seus aditamentos. }\end{array}$ \\
\hline $\begin{array}{l}\text { Resolução } n^{\circ} 1 \\
2018\end{array}$ & $\begin{array}{l}\text { Estabelece diretrizes e normas para oferta dos cursos de pós-graduação lato sensu } \\
\text { denominados cursos de especialização, no âmbito do Sistema Federal de Educação } \\
\text { Superior. }\end{array}$ \\
\hline $\begin{array}{l}\text { Resolução n }{ }^{\circ} 4 \\
2018\end{array}$ & Altera o inciso I do Artigo $2^{\circ}$ da Resolução CNE/CES nº 1, de 06 de abril de 2018. \\
\hline
\end{tabular}

Fontes diversas.

Org. DOMINGUES, A. T. 2019.

Podemos visualizar que a legislação vem se atualizando e modificando no que diz respeito aos cursos em EaD no Brasil. Essas normas representam o processo de criação e expansão da modalidade no país, principalmente após a instituição da UAB.

No Mato Grosso do Sul os cursos a distância nas instituições públicas surgiram e expandiram no pós anos 2000, devido ao avanço das tecnologias necessárias a essa modalidade de ensino e aos investimentos por parte do governo federal nesse período. Atualmente temos quatro instituições públicas que oferecem cursos na modalidade EaD. São elas: Instituto Federal de Mato Grosso do Sul (IFMS), Universidade Estadual de Mato Grosso do Sul (UEMS), 


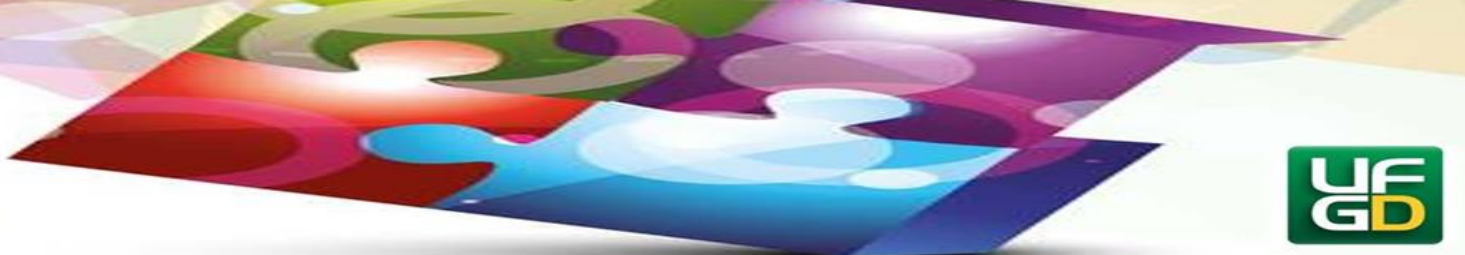

Universidade Federal da Grande Dourados (UFGD) e Universidade Federal de Mato Grosso do Sul (UFMS).

O IFMS foi criado pela Lei $\mathrm{n}^{\circ} 11.892$, de 29 de dezembro de 2008 com 10 Câmpus (Aquidauana, Campo Grande, Corumbá, Coxim, Dourados, Jardim, Naviraí, Nova Andradina, Ponta Porã e Três Lagoas - Ver Figura 01).

Figura 01 - Câmpus do IFMS em Mato Grosso do Sul - 2019.

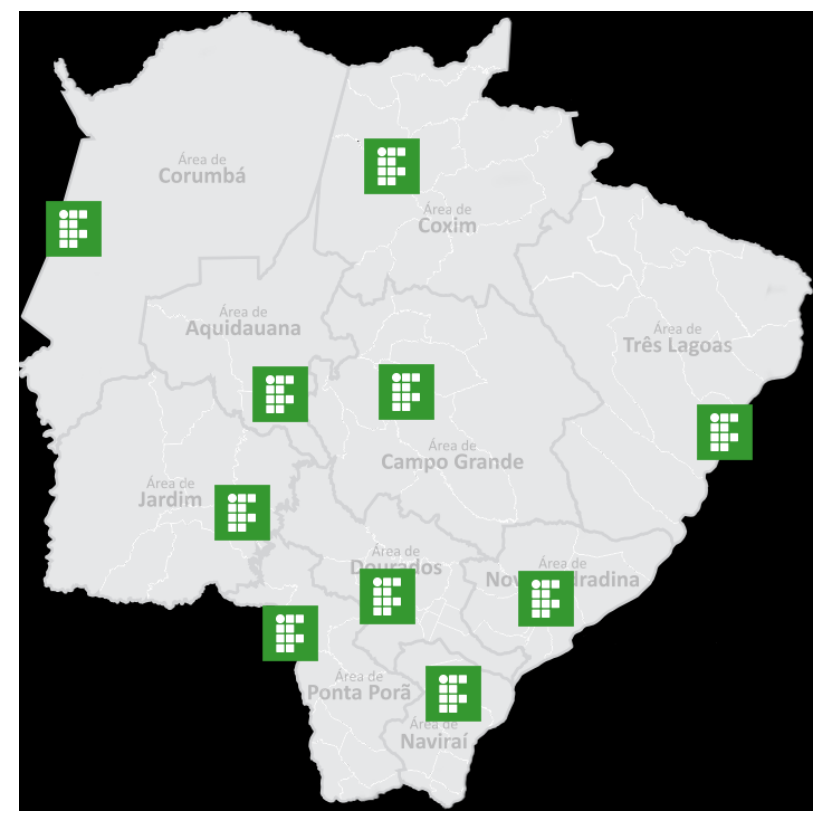

Fonte: IFMS, 2019. Disponível em: http://www.ifms.edu.br/acesso-a-informacao/institucional/estruturaorganizacional.

Atualmente oferece cursos presenciais e a distância em todos os seus campus que vão desde cursos de apoio as atividades presenciais, capacitações dos seus servidores, extensões até cursos de graduação e pós-graduação (Quadro 2).

Quadro 2 - Cursos oferecidos pela EaD no IFMS - 2019. 


\begin{tabular}{|l|l|}
\hline Cursos EaD & Campi \\
\hline Espanhol Básico I & $\begin{array}{l}\text { Aquidauana, Dourados, Jardim, Naviraí, Ponta Porã, Três } \\
\text { Lagoas }\end{array}$ \\
\hline Inglês Básico I & Dourados, Jardim, Nova Andradina e Três Lagoas \\
\hline Inglês Básico I e II & Aquidauana, Coxim, Naviraí e Nova Andradina \\
\hline Operador de Computador & $\begin{array}{l}\text { Aquidauana, Campo Grande, Corumbá, Coxim, } \\
\text { Dourados, Jardim, Naviraí, Ponta Porã e Três Lagoas }\end{array}$ \\
\hline Técnico em Administração & $\begin{array}{l}\text { Aquidauana, Corumbá, Coxim, Dourados, Jardim, } \\
\text { Naviraí, Nova Andradina e Ponta Porã }\end{array}$ \\
\hline $\begin{array}{l}\text { Técnico em Administrador de } \\
\text { Redes de Computadores } \\
\text { (Netacademy) }\end{array}$ & Campo Grande \\
\hline Técnico em Edificações & Jardim \\
\hline $\begin{array}{l}\text { Técnico em Manutenção e } \\
\text { Suporte em Informática }\end{array}$ & $\begin{array}{l}\text { Aquidauana, Campo Grande, Corumbá, Coxim, Jardim, } \\
\text { Ponta Porã }\end{array}$ \\
\hline Vendedor & $\begin{array}{l}\text { Aquidauana, Campo Grande, Corumbá, Coxim, } \\
\text { Dourados, Jardim, Naviraí, Ponta Porã e Três Lagoas }\end{array}$ \\
\hline
\end{tabular}

Fonte: Instituto Federal de Mato Grosso do Sul. Disponível em: http://www.ifms.edu.br/site. Org.: DOMINGUES, A. T., 2019.

Os cursos oferecidos pelo IFMS à distância são todos cursos técnicos e profissionalizantes, ou seja, o instituto é a única instituição educacional pública que oferece cursos técnicos e profissionalizantes no interior do estado. Já as graduações e pós-graduações ofertadas pelo mesmo são presenciais.

No que concerne ao oferecimento de cursos de graduação e pós-graduação pela $\mathrm{EaD}$, temos no Mato Grosso do Sul três instituições educacionais públicas que são a UEMS, a UFGD e a UFMS.

A Universidade Estadual de Mato Grosso do Sul foi criada pela Lei Estadual no ${ }^{\circ} .461$, de 20 de Dezembro de 1993 e "tem como princípios norteadores o conhecimento e o desenvolvimento do homem e do meio num processo de integração e participação permanente" (UEMS, 2019). Atualmente a universidade tem 56 cursos em 15 cidades sul-mato-grossenses, além de três cursos a distância que estão localizados em 7 municípios (Quadro 3).

Quadro 3 - Cursos oferecidos pela EaD na UEMS - 2019.

\begin{tabular}{|c|c|}
\hline Cursos & Municípios \\
\hline
\end{tabular}




\begin{tabular}{|c|c|}
\hline Administração Pública & $\begin{array}{c}\text { Água Clara, Aparecida do Taboado, Bela Vista, } \\
\text { Camapuã, Japorã, Miranda, Paranhos }\end{array}$ \\
\hline Ciências Sociais & Água Clara, Bela Vista, Camapuã, Japorã, Miranda \\
\hline Pedagogia & Aparecida do Taboado, Paranhos \\
\hline
\end{tabular}

Fonte: Universidade Estadual do Mato Grosso do Sul. Disponível em: http://www.uems.br/graduacao. Org.: DOMINGUES, A. T., 2019

Já a Universidade Federal da Grande Dourados foi instituída com a Lei no 11.153 , de 29 de julho de 2005. Surgiu a partir do desmembramento da Universidade Federal de Mato Grosso do Sul - Campus de Dourados. Na atualidade a universidade conta com 37 cursos presenciais e/ou no formato da pedagogia da alternância e 5 cursos a distância em 9 polos EaD (Quadro 4).

Quadro 4 - Cursos oferecidos pela EaD na UFGD - 2019.

\begin{tabular}{|c|c|}
\hline Cursos & Municípios \\
\hline Administração Pública & Costa Rica, Porto Murtinho \\
\hline Bacharelado em Letras Libras & Dourados \\
\hline Licenciatura em Computação & $\begin{array}{c}\text { Água Clara, Bataguassu, Bela Vista, Camapuã, Costa Rica, } \\
\text { Miranda, Porto Murtinho, Rio Brilhante, São Gabriel do } \\
\text { Oeste }\end{array}$ \\
\hline Licenciatura em Letras Libras & Dourados \\
\hline Licenciatura em Pedagogia & Bataguassu, Japorã, Miranda, Porto Murtinho \\
\hline
\end{tabular}

Fonte: Universidade Federal da Grande Dourados. Disponível em: https://portal.ead.ufgd.edu.br/. Org.: DOMINGUES, A. T., 2019.

No caso dos cursos disponibilizados pela EaD da UFGD, existe um diferencial das demais instituições sul-mato-grossense que é a oferta de cursos em sua sede. Os cursos de Bacharelado e Licenciatura em Letras Libras são oferecidos para o polo de Dourados, além disso, esses cursos são institucionais, ou seja, existe uma estrutura dentro da universidade para atender essa demanda (professores concursados, técnicos administrativos, etc.) e que não dependem de bolsa para seu funcionamento, pois está dentro do orçamento junto aos outros cursos. 


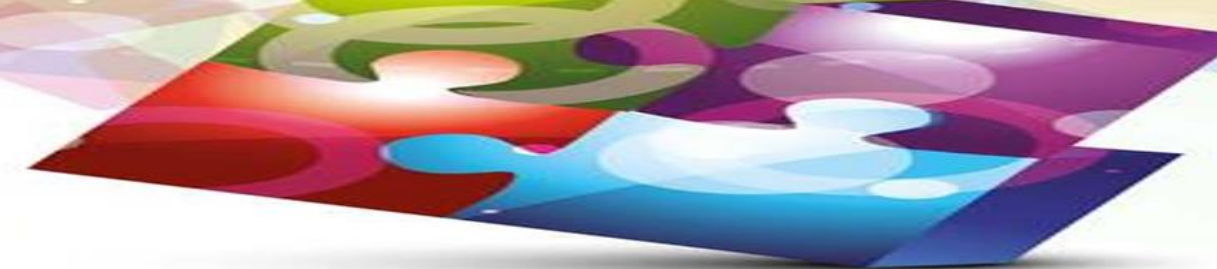

Dessa forma, a institucionalização dos cursos via $\mathrm{EaD}$ podem ser tornar uma realidade. Para isso, basta haver uma sensibilidade por parte do governo em seus diversos âmbitos, e dos reitores das universidades país afora, adotarem tais cursos com orçamento previsto dentro do escopo de cursos presenciais.

Na UFGD houve lutas constantes por parte da direção da Faculdade de Educação à Distância junto aos cursos presenciais existentes, para atender uma demanda recente, que é a Libras, uma vez que todas as licenciaturas têm que ter essa disciplina, como obrigatória em seus currículos, conforme a legislação vigente. Daí surgem os cursos institucionais à distância que são: Licenciatura em Letras Libras e Bacharelado em Letras Libras.

Além disso, surge a demanda dos professores intérpretes para atuar na educação básica dos municípios próximos a sede, como Itaporã, Douradina, Rio Brilhante, Caarapó, Ponta Porã, Fátima do Sul, Vicentina, Glória de Dourados, Deodápolis, Ivinhema, Maracaju, Laguna Carapã, entre outros. Essa demanda aumentou a procura pelo profissional formado nessa área (uma das justificativas do curso se tornar institucional).

A Universidade Federal de Mato Grosso do Sul foi criada por meio da Lei Estadual $n^{\circ}$ 2.620 com o nome de Instituto de Ciências Biológicas de Campo Grande (ICBCG). Depois passou por alterações de ampliação dentro do âmbito estadual. Em 1979 passou por uma federalização e tornou-se a UFMS, pela Lei no 6.674, de 5 de julho de 1979, sendo a maior e mais antiga instituição pública de ensino do estado.

Atualmente oferece 148 presenciais em diversas faculdades e campus (Aquidauana, Chapadão do Sul, Corumbá, Coxim, Naviraí, Nova Andradina, Paranaíba, Ponta Porã e Três Lagoas). Também oferta 7 cursos $\mathrm{EaD}$ em diversos polos UAB (Quadro 5), visando a interiorização do ensino superior dentro do âmbito estadual. O credenciamento para oferecimento de cursos de graduação e pós-graduação na modalidade à distância aconteceu em 2001, através da Portaria MEC nº 2.113, de 10 de setembro de 2001.

Quadro 5 - Cursos oferecidos pela EaD na UFGD - 2019.

\begin{tabular}{|c|c|}
\hline Cursos & Municípios \\
\hline Administração Pública & Bataguassu, Rio Brilhante, São Gabriel do Oeste \\
\hline
\end{tabular}




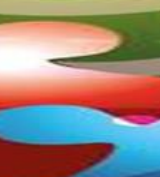

\begin{tabular}{|l|l|}
\hline Ciências Biológicas & $\begin{array}{l}\text { Água Clara, Bataguassu, Bataguassu, Bela Vista, Camapuã, Costa } \\
\text { Rica, Porto Murtinho, Rio Brilhante, São Gabriel do Oeste }\end{array}$ \\
\hline Educação Física & Bataguassu, Camapuã, Costa Rica \\
\hline $\begin{array}{l}\text { Geografia } \\
\text { Português/Espanhol }\end{array}$ & $\begin{array}{l}\text { Costa Rica, Porto Murtinho, São Gabriel do Oeste } \\
\text { Murtinho, Rio Brilhante, São Gabriel do Oeste }\end{array}$ \\
\hline $\begin{array}{l}\text { Matemática } \\
\text { Pedagogia }\end{array}$ & $\begin{array}{l}\text { Aataguassu, Bela Vista, Costa Rica, Miranda, São Gabriel do Oeste } \\
\text { Brilhante, São Gabriel do Oeste }\end{array}$ \\
\hline \multicolumn{1}{|c|}{ Municípios } \\
$\begin{array}{l}\text { Campo Grande } \\
\text { Camapuã } \\
\text { Porto Murtinho }\end{array}$ & $\begin{array}{l}\text { Relações Étnico-Raciais, Gênero e Diferenças no Contexto do } \\
\text { Ensino de História e Cultura Brasileiras. }\end{array}$ \\
\hline $\begin{array}{l}\text { Campo Grande } \\
\text { Bataguassu } \\
\text { São Gabriel do Oeste } \\
\text { Porto Murtinho } \\
\text { Rio Brilhante }\end{array}$ & $\begin{array}{l}\text { Mídias na Educação } \\
\text { Campo Grande }\end{array}$ \\
\hline
\end{tabular}

Fonte: Universidade Federal de Mato Grosso do Sul. Disponível em: https://www.ufms.br/. Org.: DOMINGUES, A. T., 2019.

Podemos visualizar que a UFMS é a instituição que mais oferece cursos, seja presencial ou à distância. Em parte, isso se deve ao tempo de existência desta universidade. Esta também tem um diferencial, pois é a única que está ofertando cursos de pós-graduação no momento em que este trabalho estava sendo realizado. Apresenta o maior quantitativo de polos que se entrecruzam com os cursos das outras instituições.

\section{Algumas considerações}

É interessante visualizar o processo de interiorização da Educação a Distância nas instituições públicas de ensino no estado do Mato Grosso do Sul se deu com mais força após a 


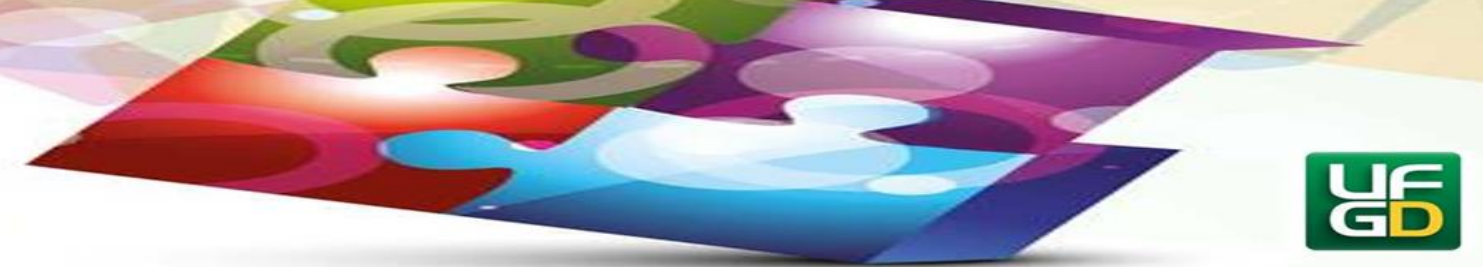

criação da UAB e o fortalecimento do fomento para essa modalidade de ensino após os anos de 2005.

Vale lembrar que a educação a distância é mais viável economicamente, se comparado aos gastos com a educação presencial, uma vez que o valor pago a um professor efetivo de um curso presencial é cerca de sete vezes maior do que o valor da bolsa pago a um professor que está atuando na $\mathrm{EaD}$ via $\mathrm{UAB}$; além do que os cursos presenciais não teriam condições de se interiorizar. Assim a EaD torna-se um meio mais econômico de expandir cursos técnicos e superiores Brasil afora, tornando-se um país mais preparado para enfrentar os desafios futuros.

O processo de ampliação das universidades durante os anos de 2005 a 2010 ocasionou uma expansão do acesso à universidade pública e, consequentemente, da educação a distância no Brasil.

A interiorização da educação a distância nas instituições se deu junto ao processo de expansão da educação superior, que por sua vez, atua de acordo com o Plano Nacional de Educação frente a ampliação dos cursos de licenciaturas como forma de diminuir as desigualdades socioeconômicas e regionais quanto à expansão da formação inicial e continuada dos professores da rede básica de educação.

A interiorização da educação a distância nas instituições públicas de ensino acontece em 20 municípios sul-mato-grossenses. Em alguns há a presença de apenas uma instituição que oferece cursos como Aparecida do Taboado, Aquidauana, Corumbá, Coxim, Jardim, Naviraí, Paranhos e Ponta Porã. Por outro lado, existem polos que tem mais de uma instituição oferecendo vários cursos, como Água Clara, Bataguassu, Bela Vista, Camapuã, Costa Rica, Dourados, Japorã, Miranda, Porto Murtinho, Rio Brilhante, São Gabriel do Oeste.

É inegável que houve um período de avanços dentro dessa modalidade de ensino nos últimos anos e, por conseguinte da interiorização do ensino superior e, consequentemente, a melhoria da qualidade de vida da população nos municípios que funcionam como polo para tais 


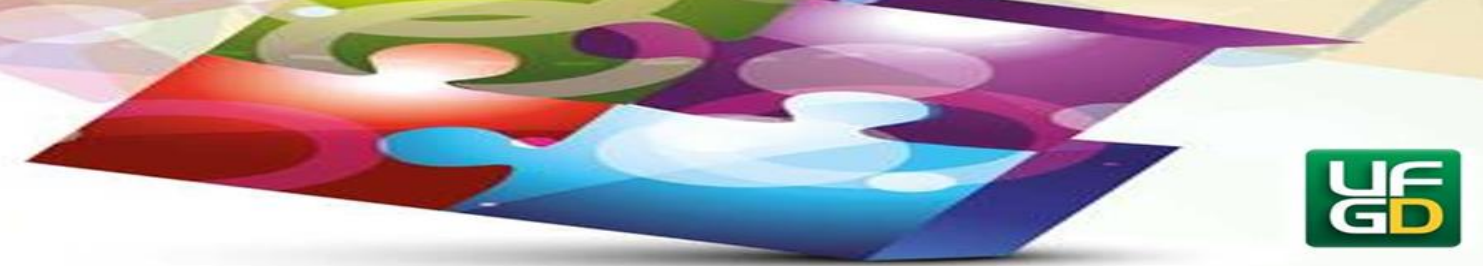

cursos. Para isso basta analisar o Índice de Desenvolvimento Humano (IDH) em qualquer um destes e notaremos que houve avanços significativos ${ }^{5}$.

As perspectivas para essa modalidade de ensino são animadoras no sentido da expansão do desenvolvimento de novas tecnologias e/ou adaptação das existentes na educação. No entanto, não são tão animadoras quando levamos em consideração a agenda neoliberal do atual governo no Brasil (2019-2022), que tem em seu âmago cortes cada vez maiores para a educação e, consequentemente para a educação a distância.

Esses ajustes no fomento trazem um cenário de estacionamento ou até de recuo no oferecimento de cursos à distância pelas instituições públicas, uma vez que estas são dependentes do custeio financeiro pelo governo federal. Com esses cortes, torna-se mais distante também, o anseio de muitas universidades em institucionalizar seus cursos que são oferecidos na modalidade a distância.

\section{Referências}

ALVES, Lucinéia. Educação à distância: conceitos e história no Brasil e no mundo. Revista Brasileira de Aprendizagem Aberta e a Distância. Volume 10, 2011. Disponível em: http://www.abed.org.br/revistacientifica/Revista_PDF_Doc/2011/Artigo_07.pdf. Acesso em: 15 ago. 2019.

AMORIM, Maria Fasura de. A importância do ensino à distância na educação profissional. Revista Aprendizagem em EAD. Volume 1, n. 1, 2008 Disponível em: https://portalrevistas.ucb.br/index.php/raead/article/view/3218. Acesso em: 15 ago. 2019.

ATLAS BRASIL. Atlas do Desenvolvimento Humano no Brasil. Disponível em: http://www.atlasbrasil.org.br/2013/. Acesso em 12 set. 2019.

BRASIL. Decreto 2.494, 10 de fevereiro de 1998. Regulamenta o art. 80 da Lei $\mathrm{n}^{\circ}$ 9.394, de 20 de dezembro de 1996, e dá outras providências. Disponível em <http://www.planalto.gov.br>. Acesso em 18/08/2019.

$5 \quad$ O IDH é uma medida tomada pela Organização das Nações Unidas (ONU) para avaliar e analisar a qualidade de vida e o desenvolvimento econômico de um país, estado ou município. Três critérios são analisados: saúde, educação e renda da população. Vamos tomar como exemplo os anos de 2000 e 2010 dos municípios de Bela Vista (0,580 e 0,698), Miranda (0,500 e 0,632) e Rio Brilhante $(0,584$ e 0,715). Se levarmos em consideração que quanto mais próximo do 1 , melhor o índice, entendemos que todos os municípios analisados melhoraram após a expansão dos cursos a distância. Disponível em: http://www.atlasbrasil.org.br/2013/. Acesso em 12 set. 2019. 


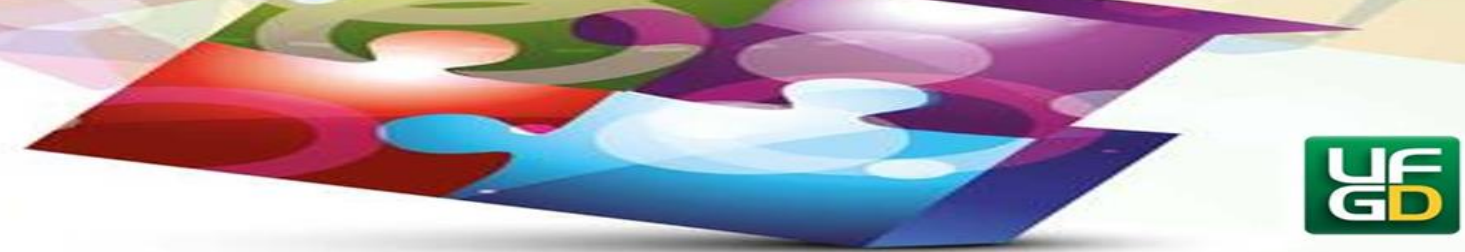

BRASIL. Decreto 2.561, 27 de abril de 1998. Altera a redação dos arts. 11 e 12 do Decreto n. ${ }^{\circ}$ 2.494, de 10 de fevereiro de 1998, que regulamenta o disposto no art. 80 da Lei n. ${ }^{\circ} 9.394$, de 20 de dezembro de 1996. Disponível em <http://www.planalto.gov.br>. Acesso em $18 / 08 / 2019$.

BRASIL. Decreto 5.622, 19 de dezembro de 2005. Regulamenta o art. 80 da Lei $\mathrm{n}^{\circ}$ 9.394, de 20 de dezembro de 1996, que estabelece as diretrizes e bases da educação nacional. Disponível em <http://www.planalto.gov.br $>$. Acesso em 18/08/2019.

BRASIL. Decreto 5.800, 08 de junho de 2006. Dispõe sobre o Sistema Universidade Aberta do Brasil - UAB. Disponível em <http://www.planalto.gov.br>. Acesso em 18/08/2019.

BRASIL. Decreto 9.057, 25 de maio de 2017. Regulamenta o art. 80 da Lei no 9.394, de 20 de dezembro de 1996, que estabelece as diretrizes e bases da educação nacional. Disponível em <http://www.planalto.gov.br>. Acesso em 18/08/2019.

BRASIL. Lei n. 6.674, de 5 de julho de 1979. Autoriza o Poder Executivo a instituir a Fundação Universidade Federal de Mato Grosso do Sul, em obediência ao disposto no art. 39 da Lei Complementar no 31, de 11 de outubro de 1977. Disponível em <http://www.planalto.gov.br>. Acesso em 14/08/2019.

BRASIL. Lei n. 9.394, de 20 de dezembro de 1996. Estabelece as Diretrizes e Bases da Educação Nacional. Disponível em <http://www.planalto.gov.br>. Acesso em 18/08/2019.

BRASIL. Lei n. 11.153, de 29 de julho de 2005. Dispõe sobre a instituição da Fundação Universidade Federal da Grande Dourados - UFGD, por desmembramento da Fundação Universidade Federal de Mato Grosso do Sul - UFMS, e dá outras providências. Disponível em <http://www.planalto.gov.br>. Acesso em 14/08/2019.

BRASIL. Lei 11.892, 29 de dezembro de 2008. Institui a Rede Federal de Educação Profissional, Científica e Tecnológica, cria os Institutos Federais de Educação, Ciência e Tecnologia, e dá outras providências. Disponível em $\langle$ http://www.planalto.gov.br $>$. Acesso em 15/08/2019.

BRASIL. Ministério da Educação. Portaria n. 4.361, de 29 de dezembro de 2004. DOU de 30 de dezembro de 2004, Seção 1, páginas 66/67.

BRASIL. Ministério da Educação. Dispõe sobre os procedimentos de regulação e avaliação da educação superior na modalidade a distância. Portaria n. 2, de 10 de janeiro de 2007.

BRASIL. Ministério da Educação. Institui o e-MEC, sistema eletrônico de fluxo de trabalho e gerenciamento de informações relativas aos processos de regulação, avaliação e supervisão da educação superior no sistema federal de educação, e o Cadastro e-MEC de Instituições e Cursos Superiores e consolida disposições sobre indicadores de qualidade, banco de avaliadores (Basis) e o Exame Nacional de Desempenho de Estudantes (Enade) e outras disposições. Portaria n. 40, de 29 de dezembro de 2010. 


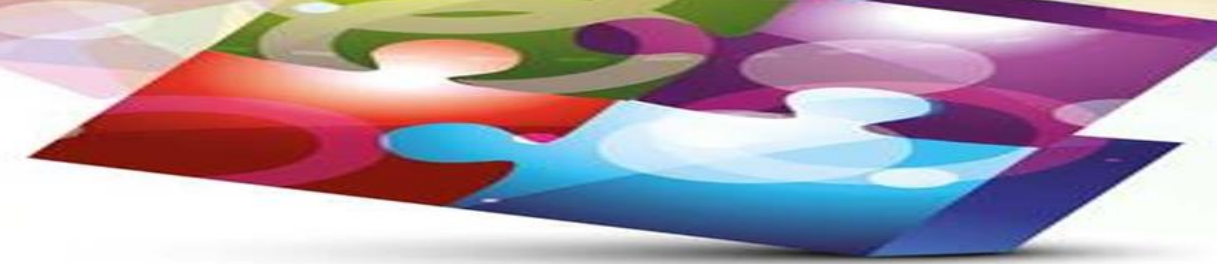

BRASIL. Ministério da Educação. Estabelece normas para o credenciamento de instituições e a oferta de cursos superiores a distância, em conformidade com o Decreto $n^{\circ} 9.057$, de 25 de maio de 2017. Portaria n. 11, de 20 de junho de 2017.

BRASIL. Ministério da Educação. Dispõe sobre os procedimentos de supervisão e monitoramento de instituições de educação superior e de cursos superiores de graduação e de pós-graduação lato sensu, nas modalidades presencial e a distância, integrantes do sistema federal de ensino. Portaria n. 22, de 21 de dezembro de 2017.

BRASIL. Ministério da Educação. Dispõe sobre o fluxo dos processos de credenciamento e recredenciamento de instituições de educação superior e de autorização, reconhecimento e renovação de reconhecimento de cursos superiores, bem como seus aditamentos. Portaria n. 23, de 21 de dezembro de 2017.

MATO GROSSO DO SUL. Lei Estadual n. 1.461, de 20 de dezembro de 1993. Autoriza o Poder Executivo a instituir a Fundação Universidade Estadual de Mato Grosso do Sul. Disponível em

<http://www.spdo.ms.gov.br/diariodoe/Index/Download/DO4938_15_01_1999 >. Acesso em $14 / 08 / 2019$.

MINISTÉRIO DA EDUCAÇÃO. Estabelece diretrizes e normas para a oferta dos cursos de pós-graduação lato sensu denominados cursos de especialização, no âmbito do Sistema Federal de Educação Superior, conforme prevê o Art. 39, § $3^{\circ}$, da Lei n 9.394/1996, e dá outras providências. Resolução n. 1, de 6 de abril de 2018.

MINISTÉRIO DA EDUCAÇÃO. Altera o inciso I do artigo $2^{\circ}$ da Resolução CNE/CES no 1 , de 6 de abril de 2018, que estabelece diretrizes e normas para a oferta dos cursos de pósgraduação lato sensu denominados cursos de especialização, no âmbito do Sistema Federal de Educação Superior, conforme prevê o Art. 39, § 3º da Lei nº 9394/1996, e dá outras providências. Resolução n. 4, de 11 de dezembro de 2018.

KENSKI, Vani Moreira. O desafio da educação a distância no Brasil. Revista Educação em Foco, Universidade Federal de Juiz de Fora, 2010. Disponível em:

https://www.ufjf.br/revistaedufoco/files/2010/02/011.pdf. Acesso em 10 de agosto de 2019.

PETRI, O. Autonomia do Aprendiz na Educação a Distância: significados e dimensões. In: PETRI, O. Educação a Distância: construindo significados. Cuiabá, 2000.

SANTOS, M. A natureza do espaço: técnica e tempo, razão e emoção. São Paulo: Ed. Hucitec, 1996.

Data do envio do trabalho: 09/08/2019

Aprovado em: 17/11/2019

Publicado em: 18/12/2019 